\title{
Subterranean electrical structure of Kozu-shima volcanic island, Japan
}

\author{
By Yoshiaki OrIHara, ${ }^{* 1}$ Masashi Kamogawa, ${ }^{* 2, \dagger}$ Akihiro TaKeuchi, ${ }^{* 1}$ \\ Hiroaki FUKASE*1 and Toshiyasu NAGAO*1 \\ (Communicated by Seiya UYEDA, M.J.A.)
}

\begin{abstract}
Following the electric current injection experiment carried out in 2009, a VLFMT (Very Low Frequency Magnetotelluric) survey has been conducted in Kozu-shima Island to obtain further information on the subterranean electrical structure that might help understanding the results of our monitoring of geoelectric potentials. A number of VAN-type pre-seismic geoelectric potential anomalies were observed in 1997-2000, even showing a remarkable "Selectivity". However, similar pre-seismic anomalies were not observed during the Izu-Island volcano-seismic swarm 2000. All these observations would require extremely high degree of heterogeneity in the subterranean electrical structure of the volcanic island and its possible time changes. Several correlations between the results of this survey and the volcanic geology of the island and ground water distribution were found. Further investigation is needed for a complete explanation of the observed phenomena.
\end{abstract}

Keywords: VLF-MT survey, apparent resistivity, phase angle, geoelectric potential, geology

\section{Introduction}

Kozu-shima Island, one of Izu volcanic islands, is located about $170 \mathrm{~km}$ south of Tokyo (Fig. 1). Size of this island is approximately $5 \mathrm{~km}$ in east-west and $6.5 \mathrm{~km}$ in north-south directions with $24 \mathrm{~km}$ of circumference. According to geological studies, ${ }^{1)-3)}$ the island grew in the activity of several rhyolitic monogenetic volcanoes with pyroclastic flow and base surge (Fig. 2). Bedrock of the island is Kaesuhama lava of Miocene age which crops out at the very north tip of the island and the latest volcano is Mt. Tenjosan. According to Shoku Nihon Koki, a Japanese old historical literature, published in 869 A.D., Mt. Tenjosan erupted in 838 A.D. ${ }^{4)}$ The order of each eruption comprising the monogenetic volcanoes has been investigated. ${ }^{2), 3), 5)}$ Although Issiki ${ }^{3)}$ reported that Nagahama lava was created by monogenetic volcanoes, Yokoyama et al. ${ }^{6)}$ found from ESR investigation that Nagahama lava consists of two different lavas, Nagumiwan and Sawajiri lavas.

\footnotetext{
*1 Earthquake Prediction Research Center, Tokai University, Shizuoka, Japan.

*2 Department of Physics, Tokyo Gakugei University, Tokyo, Japan.

$\dagger$ Correspondence should be addressed: M. Kamogawa, 4-1-1 Nukuikitamachi, Koganei, Tokyo 184-8501, Japan (e-mail: kamogawa@u-gakugei.ac.jp).
}

Seismic activity around Kozu-shima was predominant in the northeast-southwest oriented zone extending from Zenisu Ridge until the 2000 earth-

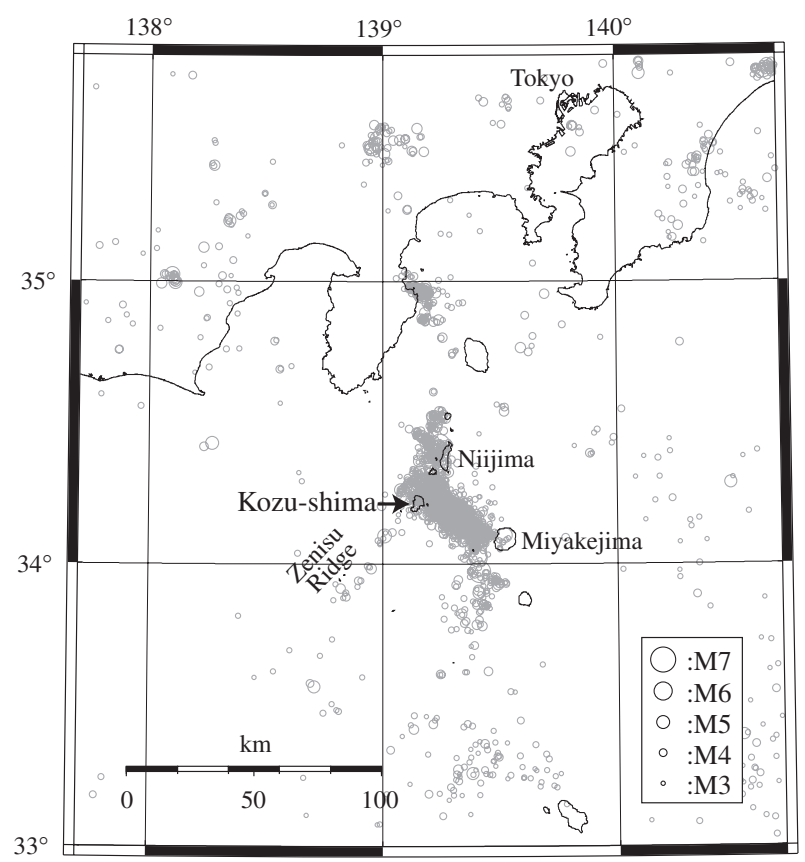

Fig. 1. Seismicity around Kozu-shima $(\mathrm{M} \geq 3.0$, depth $\leq 50 \mathrm{~km})$ from January 1, 1996 to December 31, 2005, reported by Japan Meteorological Agency. 


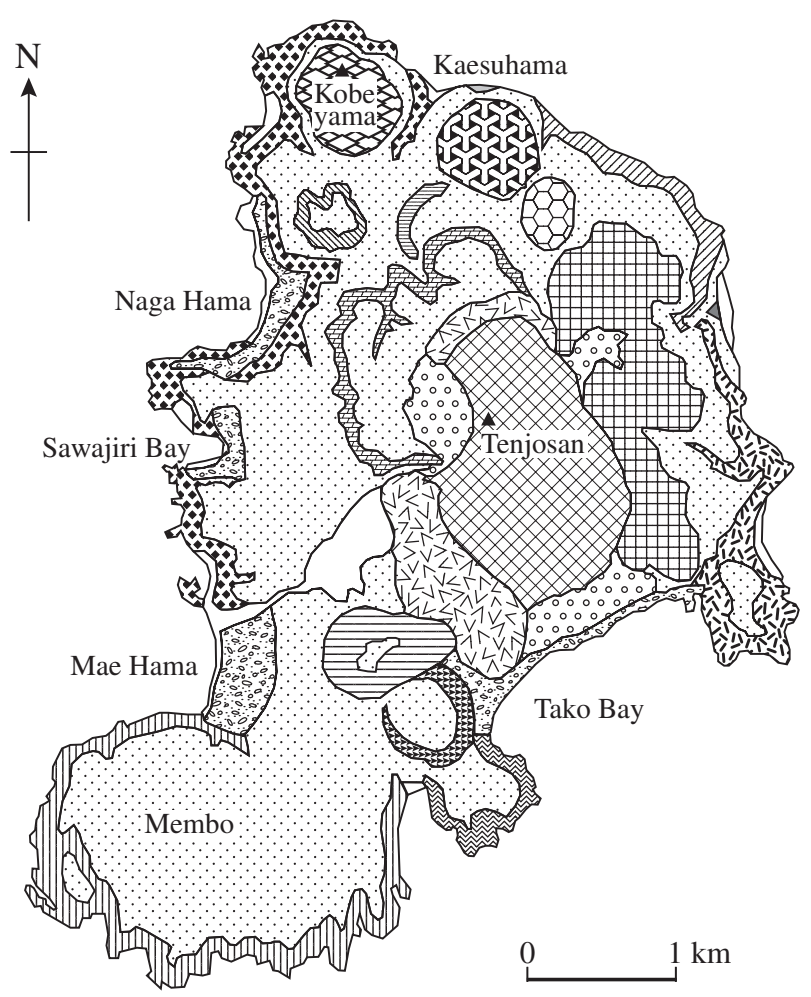

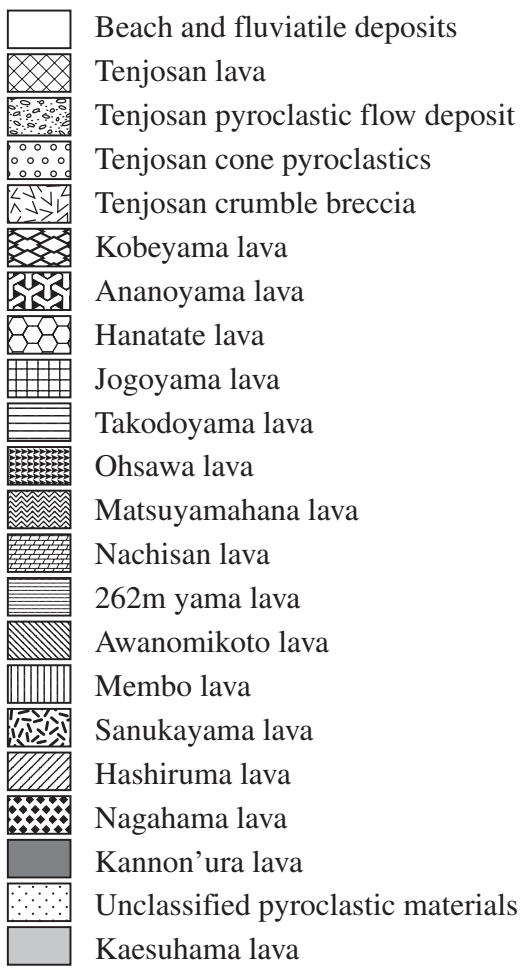

Fig. 2. Geological map of Kozu-shima. (Modified from Isshiki ${ }^{3}$ )

quake (EQ hereafter) swarm in Izu Islands associated with the eruption of Miyake-jima Island. The predominant trend of seismicity changed to the northwest-southeast one with the initiation of the swarm (Fig. 1). The swarm included 3 M6-class EQs. ${ }^{7}$ )

In Greece, pre-seismic geoelectric potential anomalies, named seismic electric signals (SES), have been observed by VAN group. ${ }^{8)}$ The SES shows the following aspects, of which feature is called "Selectivity". There are only selected observation sites which are sensitive to SES (sensitive sites). A sensitive site is sensitive only to SES from some specific focal area(s), which are not always in close proximity. The Selectivity is considered to be originated from the inhomogeneity of the subterranean electrical structures, i.e., SES goes only through conductive channels. In Japan, geoelectric potential monitoring in Kozu-shima was conducted to detect pre-seismic transient anomalous change since 1997 until the monitoring station was destroyed by EQ shaking and typhoon in June 2000. A number of VAN-type anomalies were observed ${ }^{9)}$ before EQs which occurred around the island. They even showed a remarkable "Selectivity". Although another type of intermittent anomalous telluric current was observed for two months before the 2000 swarm in the nearby Niijima Island, no anomalous telluric current was detected before the swarm in Kozu-shima. ${ }^{10)}$ What this observation implies is not clear at the moment. It might have been another aspect of the "Selectivity" because, as mentioned above, the locations of the swarm EQ were different from those of pre-swarm era or the swarm modified the "Selectivity" property, i.e., the electrical structure of Kozu-shima. As one of the first steps to investigate the apparently heterogeneous conductive structure of Kozu-shima, an electric current injection experiment was carried out recently. ${ }^{11)}$ Present study is a follow up investigation by means of VLF-MT (Very Low Frequency Magnetotelluric) method.

\section{VLF-MT method}

VLF-MT is one of subsurface resistivity structure survey methods using artificial radio waves. Electromagnetic waves in VLF band ranging from 3 to $30 \mathrm{kHz}$ penetrate into shallower part of the sea and earth and propagate long distance through the earthionosphere wave guide. They have been widely used as a global positioning system for submarines, ships, and airplanes. In the present study, our instrument of 
VLF-MT survey, developed by Tierra Tecnica, Japan, uses radio waves from Ebino VLF transmitter in southern Kyushu $\left(32^{\circ} 4^{\prime} 59^{\prime \prime} \mathrm{N} 130^{\circ} 49^{\prime} 41^{\prime \prime} \mathrm{E}\right)$, of which frequency is $22.2 \mathrm{kHz}$. The advantage of this type of survey is the portability of instruments and short-time needed for measurement, while the disadvantage in our case is the limited information because of the use of only a fixed frequency of single transmitter.

The VLF-MT method measures electromagnetic response of the ground to the radio waves. The apparent resistivity and the phase angle are derived from the ratio between the perpendicular components of the horizontal electric field and the magnetic field. According to Cagniard, ${ }^{12}$ ) the apparent resistivity $\rho(\Omega \mathrm{m})$ is given by

$$
\rho=0.2 T\left(E_{x} / B_{y}\right)^{2},
$$

where $T$ (sec) is period of the radio wave, and two orthogonal components of radio waves, $E_{x}(\mu \mathrm{V} / \mathrm{m})$ and $B_{y}(\mathrm{nT})$ are the intensity of the electric and magnetic field. The phase angle $\varphi$ (degree) is given by

$$
\varphi=\arg \left(E_{x} / B_{y}\right)
$$

The phase angle provides us with the information of apparent resistivity changes between shallower and deeper parts. Phase angle of 45 degrees indicates the homogeneous structure. Under the assumption of a two layer model, phase angle is less than 45 degrees when the resistivity of the shallower layer is smaller than that of the deeper layer. On the other hand, when the resistivity of the shallower layer is greater than that of the deeper layer, it shows more than 45 degrees. The skin depth $\delta(\mathrm{m})$ of the homogeneous half space structure is shown as

$$
\delta=503 \sqrt{\rho / f}
$$

where $\rho(\Omega \mathrm{m})$ is the apparent resistivity and $f(\mathrm{~Hz})$ is frequency. ${ }^{12)}$ The skin depth is regarded as approximately showing the sounding depth. For example, when the apparent resistivity $\rho$ is $100 \Omega \mathrm{m}$ and $1000 \Omega \mathrm{m}$, the sounding depth for $f=22.2 \mathrm{kHz}$ is estimated at $34 \mathrm{~m}$ and $107 \mathrm{~m}$.

The VLF-MT method is useful for subsurface resistivity mapping such as ancient tomb ${ }^{13)}$ and underground tunnel. ${ }^{14)}$ Sato and Nishitani ${ }^{15)}$ and Yamaguchi et al. ${ }^{16)}$ conducted the subsurface fault survey, and Kasai ${ }^{17), 18)}$ inferred the geological structure of the area of scarce outcrop information such as Mt. Yatsugatake.

In Kozu-shima, Tokyo Metropolitan Government $^{19)}$ made a VLF-MT survey at twenty points,

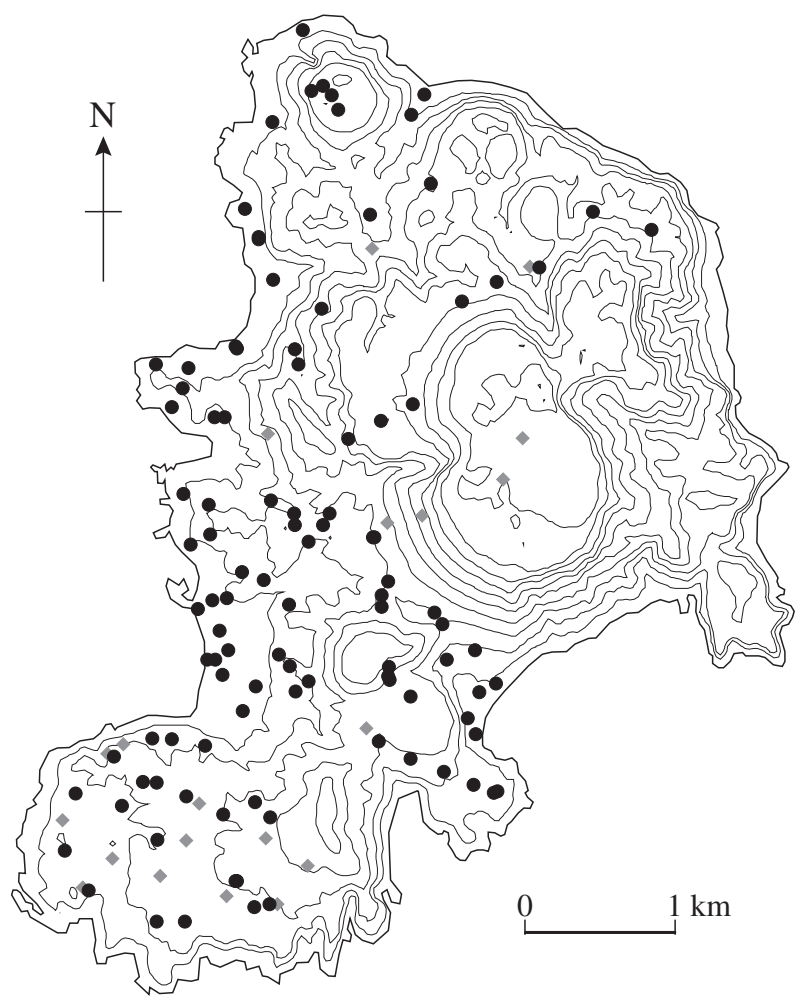

Fig. 3. Points of measurement. Contour line is drawn every $50-\mathrm{m}$ altitude. Solid circles and gray rhombi denote the points measured by this study and by the Tokyo Metropolitan Government. ${ }^{19)}$

mainly at Membo area (see Fig. 3). Here, we also conducted a VLF-MT survey for mapping the resistivity of the whole island.

\section{Results and discussion}

The largest measured value of the apparent resistivity was more than $10000 \Omega \mathrm{m}$ at Mt. Tenjosan, ${ }^{19)}$ whereas, the smallest one was $10 \Omega \mathrm{m}$ at Sawajiri Bay (see Fig. 2). Since they are ranging in three orders of magnitude, the contour map is shown in a logarithmic scale (Fig. 4). Figure 5 shows the phase angles of measured points. White, gray and black symbols indicate more than 46 degrees, 44 to 46 degrees and less than 44 degrees, respectively.

Our measurement results were found to be divided in six groups (Fig. 5). Group A includes 33 points in Membo area (Fig. 2). Among them, the apparent resistivities of 30 points were of the order of $100 \Omega \mathrm{m}$ and three others indicated more than $1000 \Omega \mathrm{m}$. Concerning the phase angles, 28 points showed from 20 to 40 degrees which signified the resistivity of the deeper layer was greater than that of 


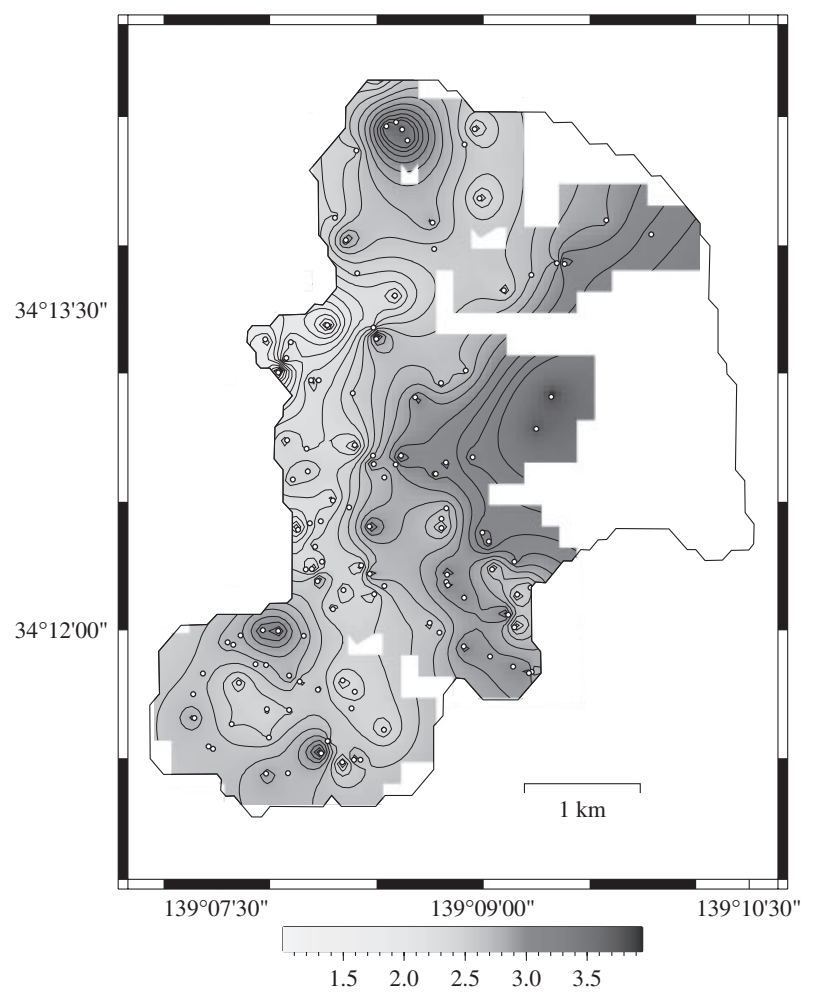

$\log$ resistivity $(\mathrm{ohm}-\mathrm{m})$

Fig. 4. The contour map of the apparent resistivity.

the shallower layer. According to Taniguchi ${ }^{2}$ and Isshiki, ${ }^{3)}$ Membo area consists of Membo lava and pyroclastic materials covering the lava (Fig. 2). The thickness of the pyroclastic materials was estimated to be 20 to $50 \mathrm{~m} .{ }^{20)}$ As mentioned earlier, average of resistivities at 30 points is of the order of $100 \Omega \mathrm{m}$, which corresponds to the skin depth of around $60 \mathrm{~m}$. It meant the "sounding depth" reached the lava. Hence, the high resistivity materials in the deeper layer were inferred to be the Membo lava. One of the points with more than 46 degrees of phase angle was located in the central part of Membo area. Its apparent resistivity and skin depth were $150 \Omega \mathrm{m}$ and $41 \mathrm{~m}$. The sounding depth at this point might have not reached the lava, because the estimated maximum thickness of the pyroclastic materials was $50 \mathrm{~m}^{20)}$ The 3 measurement points with more than $1000 \Omega \mathrm{m}$ and 20 to 40 degrees of phase angle suggest that the lava reached near the ground surface.

Group B in Fig. 5 consists of unclassified pyroclastic materials, Takodoyama lava, Ohsawa lava and Matsuyamahana lava (Fig. 2). We measured at 11 sites in this area. The apparent resistivites of 6 points showed more than $1000 \Omega \mathrm{m}$. The phase angles

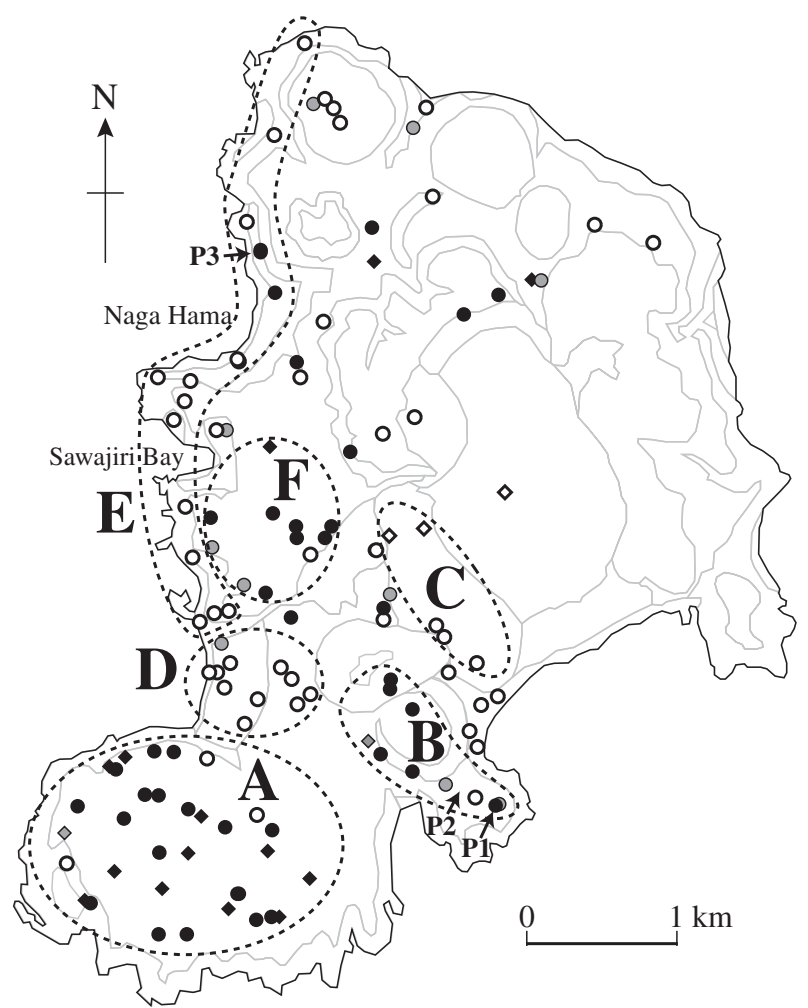

Fig. 5. The phase angles and their grouping of distribution. Circles and rhombi indicate the same as in Fig. 3. White, gray and black symbols show more than 46 degree, 44 to 46 degrees and less than 44 degree respectively. The groups are marked A, B, C, D, E and F for discussion in the text. P1 to P3 show the locations of photos in Fig. 6.

of 7 points were less than 40 degrees, indicating that the deeper layer has higher resistivity than the shallower one, and the thickness of pyroclastic materials might be thin. Figures 6(a) and (b) show the outcrops of P1 and P2 in Fig. 5. The outcrop of P1 may show unclassified pyroclastic materials. This might be secondary deposits because the grain size and preferred orientation were irregular. The outcrop of P2 also belongs to unclassified pyroclastic materials (Fig. 2). However, a large rock which might be lava suggests that the lava reaches the vicinity of the ground level.

Five points of measurement in Group C belong to Tenjosan crumble breccia (Fig. 2). The apparent resistivities ranged from 920 to $2300 \Omega \mathrm{m}$. The phase angles were more than 50 degrees. It shows the deeper layer is more conductive than the shallower one. This might indicate the existence of underground water perhaps flown from Mt. Tenjosan. 
(a)

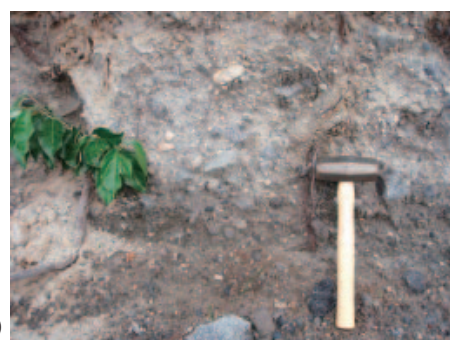

(b)

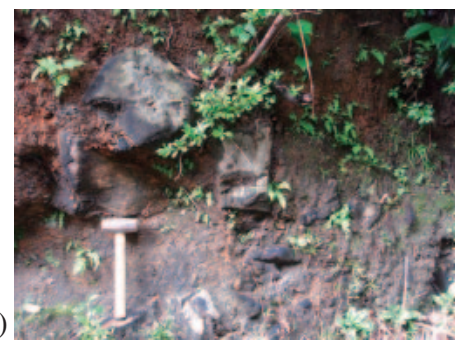

(c)

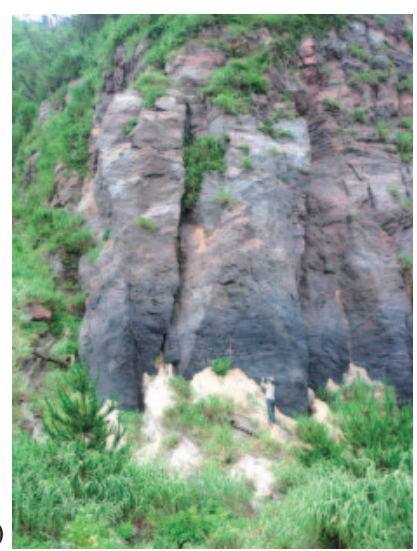

Fig. 6. Outcrops at (a) P1, (b) P2 and (c) P3 in Nagahama lava, of which locations are shown in Fig. 5.

Group D is located in a villagery where most of the population and village facilities such as village office and telephone company (NTT) are located. The geological map (Fig. 2) shows Tenjosan pyroclastic flow deposit, unclassifiled pyroclastic materials, beach and fluviatile deposits. All measured apparent resistivities were of the order of $100 \Omega \mathrm{m}$. One phase angle showed 46 degrees and the others were more than 50 degrees, indicating the deeper layer is more conductive. This area is located on the catchment area of the Kozu River ${ }^{21)}$ and the vicinity of the coastline. Underground water might be the cause of the high conductivity of the deeper layer.

Group E consists of 19 measurements along the coastline. The geology is Nagahama lava and Tenjosan pyroclastic flow deposit (Fig. 2). Two apparent resistivities were $770 \Omega \mathrm{m}$ and $950 \Omega \mathrm{m}$, and the others were less than $400 \Omega \mathrm{m}$, especially 5 data showed less than $50 \Omega \mathrm{m}$. These low resistivities may be caused by the infiltration of sea water. The apparent resistivities of $770 \Omega \mathrm{m}$ and $950 \Omega \mathrm{m}$ were measured at P3 (Figs. 5 and 6). Their phase angles were 42 and 43 degrees. The thin pyroclastic flow deposit might be the cause of such a high resistivity. Fifteen data of less than $400 \Omega \mathrm{m}$ resistivities and more than 50 degrees phase angles mean that the upper layer is more conductive. Such structure might also be caused by the infiltration of sea water.

The geology of Group F is unclassified pyroclastic materials. Nine data out of 11 measurements were of the order of $100 \Omega \mathrm{m}$ and the rest of two data showed $2000 \Omega \mathrm{m}$ and $1100 \Omega \mathrm{m}$. As regards the phase angle, 8 data showed less than 44 degrees. The feature of $100 \Omega \mathrm{m}$ resistivity and less than 44 degrees of phase angle is the same as that of Group A. Hence, the double layer structure, i.e. pyroclastic materials covering the lava, is analogized.

\section{Conclusions}

We conducted a VLF-MT survey in Kozu-shima Island. Several correlations between the results of this survey and the geology of the island have been found. For example, on Membo area (Group A), assuming the double layer structure, we can estimate from the phase angle that the lava was covered with pyroclastic materials. Such structure was also found in the area between Sawajiri Bay and Mt. Tenjosan (Group F). Thus, the VLF-MT survey helps to map the underground structure. Furthermore, the VLF-MT survey might be useful for mapping ground water distribution. However, this study is only the very beginning of the investigation on the extremely heterogeneous subterranean elec- 
trical structures, of which detailed information would be needed for clarification of the physical mechanism of the observed characteristic features of pre-seismic electric signals observed at Kozu-shima Island.

\section{Acknowledgments}

We thank Mr. T. Sakurai, Mr. M. Kawashima, Mr. H. Matsue and Mr. H. Maeda of Kozu-shima Village Office for supporting this study. The authors are also grateful to Ms. Y. Arai (Tokyo Gakugei University) and Mr. T. Saka (Tokai University) for their assistance to this survey and Mr. Y. Noda (Tierra Tecnica Corporation) for useful comments. We borrowed the VLF-MT instrument from Earthquake Research Institute, The University of Tokyo. This research was partially supported by the Ministry of Education, Culture, Sports, Science and Technology (MEXT) of Japan, - Grant-in-Aid for Young Scientists (B), No. 21710180, 2009 (M.K.), Observation and Research Program for Prediction of Earthquakes and Volcanic Eruptions (T.N.), and Scientific Research (C), No. 20510171, 2008 (M.K.) - , Ito Science Foundation, 2007 (M.K.) and Grant-in-Aid of Fukada Geological Institute, 2009 (Y.O. and M.K.). We deeply thank Prof. S. Uyeda (M.J.A.) for his guidance.

\section{References}

1) Tsuya, H. (1937) On the volcanism of the Huzi volcanic zone, with special reference to the geology and petrology of Idu and the southern islands. Bull. Earthq. Res. Inst. 15, 215-357.

2) Taniguchi, H. (1977) Volcanic geology of Kozushima, Japan. Bull. Volcanol. Soc. Jpn., 2nd Ser. 22 (3), 133-147 (in Japanese).

3) Isshiki, N. (1982) Geology of the Kozushima district. Quadrangle series scale 1:50,000. Geol. Surv. Japan, Hachijojima (9) No. 2 (in Japanese).

4) Issiki, N., Ono, K., Hirayama, J. and Ohta, R. (1965) Carbon-14 dating. Chishitsu News 133, 20-27 (in Japanese).

5) Tsuya, H. (1930) Geographical features and the geological structure of Izu Kozushima volcanic island, Japan. Geogr. Rev. Jpn. 3, 453-469 (in Japanese).

6) Yokoyama, T., Shimada, A., Umemura, T. and Toyoda, S. (2004) ESR Ages of rhyolitic monogenetic volcanoes in Kozushima, Japan. Bull. Volcanol. Soc. Jpn. 49 (1), 23-32 (in Japanese).

7) Toda, S., Stein, R.S. and Sagiya, T. (2002) Evidence from the AD 2000 Izu islands earthquake swarm that stressing rate governs seismicity. Nature 419, 58-61.

8) Varotsos, P. and Lazaridou, M. (1991) Latest aspects of earthquake prediction in Greece based on seismic electric signals. Tectonophysics 188, 321347.

9) Orihara, Y., Noda, Y., Nagao, T. and Uyeda, S. (2002) A possible case of SES selectivity at Kozu-shima Island, Japan. J. Geodyn. 33, 425432.

10) Uyeda, S., Hayakawa, M., Nagao, T., Molchanov, O., Hattori, K., Orihara, Y. et al. (2002) Electric and magnetic phenomena observed before the volcanoseismic activity 2000 in the Izu Island Region, Japan. Proc. Natl. Acad. Sci. USA 99, 7352-7355.

11) Orihara, Y., Kamogawa, M., Nagao, T. and Uyeda, S. (2009) Heterogeneous electrical structure of Kozu-shima volcanic island, Japan. Proc. Jpn. Acad., Ser. B 85, 476-484.

12) Cagniard, L. (1953) Basic theory of the magnetotelluric method of geophysical prospecting. Geophysics 18, 605-635.

13) Nishitani, T. (1995) Magnetotelluric survey of the Iwatoyama-Kofun in Yame city. Tech. Rep. IEICE. SANE 95-29, 21-25 (in Japanese).

14) Nishitani, T. (1998) Investigation of underground resistivity structure using VLF-MT method. Akita University Engineering Resources Faculty of Material Resources System Research Facility Reporting 63, 73-80 (in Japanese).

15) Satoh, H. and Nishitani, T. (1993) Resistivity structure beneath the Senya fault in Akita Prefecture. Akita University Mines Faculty Resources Science Research Facility Reporting 58, 53-58 (in Japanese).

16) Yamaguchi, S., Murakami, T. and Inokuchi, H. (2001) Resistivity mapping using the VLF-MT method around surface fault ruptures of the 1995 Hyogo-ken Nanbu earthquake, Japan. Isl. Arc 10, 296-305.

17) Kasai, H. (1996) The application of the VLF-MT survey to volcanic structure-The structure and origin of conical hills on Nirasaki mudflow, Japan-. J. Jpn. Soc. Eng. Geol. 37 (5), 12-23.

18) Kasai, H. (1998) The application of the VLF-MT survey to volcanic structure-The structure and origin of conical hills on Nirasaki mudflow, Japan (2) - . J. Jpn. Soc. Eng. Geol. 39 (5), 433-442.

19) Tokyo Metropolitan Government (1990) Report on characteristic features of volcanic eruptions in IzuIslands, Japan (Volume on Kozushima-Island). Tokyo Metropolis disaster prevention conference, p. 63 (in Japanese).

20) Suga, K., Kobayashi, K., Kanemaki, M., Miyahara, T. and Endo, K. (1992) Pyroclastic deposits in southern part of Kozushima. Bull. Volcanol. Soc. Jpn. 37 (2), 71-83 (in Japanese).

21) Shiobara, T. (1962) Hydrogeology of Kozu Island, Tokyo. J. Jpn. Soc. Eng. Geol. 3 (3), 43-57 (in Japanese).

(Received Sept. 15, 2010; accepted Sept. 24, 2010) 